\title{
The Extraction of a Natural Dye Berberine and Evaluation of its Corrosion Inhibition properties for P110SS Steel
}

\author{
Li Na ${ }^{1, *}$, Guo Hui ${ }^{1}$, Zhao Peng ${ }^{1}$, Zhang Xin ${ }^{1}$, Zhang Lihua ${ }^{1}$, Ambrish Singh ${ }^{2}$ \\ ${ }^{1}$ Shaanxi University of Chinese Medicine, the new district of Xian-Xianyang, Shaanxi, 712046, \\ P.R.China. \\ ${ }^{2}$ School of Materials Science and Engineering, Southwest Petroleum University, 8 Xindu district- \\ 610500, Chengdu city, Sichuan province, P. R.China. \\ *E-mail: linashaanxi@126.com
}

doi: $10.20964 / 2019.02 .62$

Received: 8 October 2018 / Accepted: 21 November 2018 / Published: 5 January 2019

\begin{abstract}
Root extract of Coptis chinensis was used to extract berberine a cationic dye to investigate the corrosion inhibition tendency towards P110SS steel in 3.5\% NaCl solution containing carbon dioxide. The investigation included electrochemical studies and surface studies. Electrochemical impedance spectroscopy and potentiodynamic polarization methods were used to detect the electrochemical changes at the surface. The surface was explored through scanning electron microscope (SEM), UV-visible, and contact angle methods. The diameter of the Nyquist plots increased with higher concentration of the inhibitor suggesting better inhibition efficiency. The changes in the anodic and cathodic curves suggested both the mechanism were equally modified and therefore the inhibitor was categorized in the mixed type. The SEM images showed the smooth surface of the metal with inhibitor indicating the effective action of the inhibitor on the surface. The UV-visible and contact angle methods also vindicated the effective action of the inhibitor for corrosion of P110SS steel in the aggressive solution. Out of the several isotherms tested for adsorption, Langmuir was found to be the best fit.
\end{abstract}

Keywords: Berberine, SEM, UV-Visible, Inhibitor, Corrosion, EIS

\section{$\underline{\text { FULL TEXT }}$}

(C) 2019 The Authors. Published by ESG (www.electrochemsci.org). This article is an open access article distributed under the terms and conditions of the Creative Commons Attribution license (http://creativecommons.org/licenses/by/4.0/). 